3

\title{
Recreational Fisheries: Socioeconomic Importance, Conservation Issues and Management Challenges
}

\author{
Robert Arlinghaus ${ }^{1}$ and Steven J. Cooke ${ }^{2}$ \\ ${ }^{1}$ Department of Biology and Ecology of Fishes, Leibniz-Institute \\ of Freshwater Ecology and Inland Fisheries, Berlin, Germany \& \\ Inland Fisheries Management Laboratory, Faculty of Agriculture \\ and Horticulture, Humboldt-University at Berlin, Germany \\ ${ }^{2}$ Institute of Environmental Science and Department of Biology, \\ Carleton University, Ottawa, Canada
}

\section{Introduction}

Human exploitation of fish and other aquatic animals such as crustaceans and mammals is virtually ubiquitous on Earth and since ancient times has provided humanity with food, income and other social goods such as recreation. Fishing where the primary objective is not to produce food or generate income through the sale or trade of fishing products is commonly termed 'recreational fishing' or 'angling' (Arlinghaus et al., 2007). In most developed or industrialised societies of the temperate regions, recreational fisheries have long represented the major use of aquatic wildlife, thus constituting the dominant fishing activity in limnetic surface waters (Arlinghaus et al., 2002). Furthermore, the importance of recreational fishing in many coastal areas (Coleman et al., 2004) and less developed nations (Cowx, 2002) is increasing rapidly.

Recreational Hunting, Conservation and Rural Livelihoods: Science and Practice. Edited by Barney Dickson, Jon Hutton and William M. Adams @ 2009 Blackwell Publishing Ltd. ISBN: 978-1-405-16785-7 
This paper treats recreational fishing as the aquatic complement to the recreational hunting of terrestrial organisms (primarily birds and mammals). Its objectives are to: (i) present a universal definition of recreational fishing and common capture methods; (ii) report the global magnitude of recreational fishing participation; (iii) identify conservation issues in recreational fishing; and (iv) discuss the management challenges in reconciling fish resource use and conservation in recreational fishing. This chapter discusses both freshwater and marine environments but, due to space limitations and the diversity of conditions in different parts of the world, only selected examples are provided.

\section{Definitions}

Definitions of recreational fishing vary depending on the origin and the cultural perception of the activity (Aas, 2002). Many of the definitions proposed by researchers and international fisheries bodies (e.g., Food and Agricultural Organization of the United Nations (FAO), 1997; Aas, 2002; Pitcher \& Hollingworth, 2002) are not suitable to describe all forms of recreational fishing. For example, most of the definitions of recreational fishing make reference to the motives of recreational fishers such as fishing for 'enjoyment' (Policansky, 2002), 'sport' (FAO, 1997) or 'fun' (Pitcher \& Hollingworth, 2002). However, the motives of recreational fishers are diverse and differ from one person to another (Fedler \& Ditton, 1994). Hence, specific motives such as 'sport' are unsuitable for defining recreational fishing as they do not embrace the attitudes and value systems of all recreational fishers.

We propose that recreational fishing can be defined generically by focusing on the most basic and essential level of human needs, i.e. physiological needs essential for survival, such as nutrition. If fishing contributes substantially to meeting an essential physiological need and if that physiological need cannot be easily met by a substitute activity to fishing, it is not recreational. The following definition for recreational fishing emerges:

Recreational fishing is fishing for aquatic animals that do not constitute the individual's primary resource to meet essential physiological needs.

This definition is sufficiently broad to include other animals beyond fish, such as lobsters and crabs, avoids referring to individual motives, does not 
discriminate against particular methods of fish capture (e.g. angling, gill netting), does not preclude the catch being taken for personal consumption (as long as the catch is not the primary resource to meet essential physiological needs), and does not discriminate against non-Western cultures (cf. Aas, 2002), but does distinguish commercial and purely subsistence fishing from recreational fishing. It does this because the purpose of commercial and subsistence fishing is to generate products for sale, trade or immediate consumption in order to meet primary physiological needs. Further, an employee of a company that offers guidance to tourist anglers would not be a recreational fisher, even if that person uses the same tackle, at the same spot and at the same time of the day as the tourist.

In the definition, the term 'primary resource' is important because there are recreational anglers who sell part of the catch to offset the costs of fishing (Cowx, 2002) or who trade fish informally with friends in return for other services. There are also many recreational anglers in Western societies who complement household diets with fish (Arlinghaus, 2004), and thus contribute to meeting basic physiological needs. But they do not depend primarily on the catch to meet essential physiological needs. Those needs can be met by activities other than fishing.

In Western culture where there is a clearer demarcation between working time and free time, and fishing products are usually exchanged on domestic or export markets, recreational fishing can be more succinctly defined in the following way:

Recreational fishing is fishing for aquatic animals that are not traded on domestic or export markets.

From the perspective of the individual angler, recreational fishing is therefore non-commercial fishing, but there are of course many commercial activities, such as the gear industry, that result from and are dependent on recreational fishing.

\section{Capture methods}

Recreational fishing is today predominantly conducted by angling methods, i.e. hook and line fishing. Recreational angling methods include hand line fishing, pole fishing (without a reel) or the standard fishing by rod, line and 
reel. Hence, in Western societies of the temperate regions 'recreational fishing' is typically used synonymously for 'angling' (Arlinghaus et al., 2002, 2007), simply because non-angling fishing methods, such as gill nets, are used only locally, e.g. in the Nordic countries.

The principle of capturing fish by angling is simple. The aquatic animal to be caught finds itself unable to get rid of a hooking device (e.g. a baited hook or a bait combined with a twine or a spider web) such that the animal can be lifted out of its element by means of a line. Angling typically aims at the mouth region of fishes. However, there is also a less common (and sometimes illegal) angling that purposely hits the fish along the body axis with a hook (typically called 'snagging'). Other capture methods employed in recreational fishing include spear fishing, bow fishing, rifle fishing, hand fishing, i.e. doodling, netting (fyke, gill), other forms of trapping fish etc. (Figure 3.1), but they are overall less common than angling techniques and only of local importance.
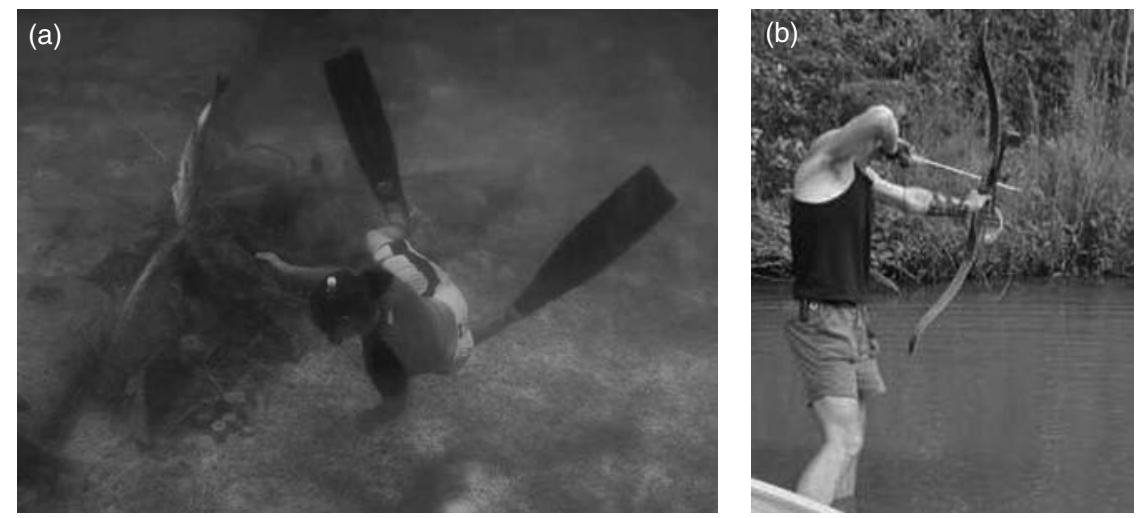

Figure 3.1 Recreational fishing techniques. (a) Spear fishing for snapper around patch reefs in the Caribbean (Credit: Andy Danylchuk). (b) Bow fishing for common carp in the US (Credit: Ohio Division of Wildlife). (c) Fly fishing for bonefish in the Bahamas with fishing guide in foreground (Credit: Steven Cooke). (d) Hand-lining for cichlids in Malawi (Credit: Setsuko Nakayama). (e) Seventyfive teams of anglers in Ontario about to begin a two day competitive angling event (i.e. tournament) for smallmouth bass (Credit: Steven Cooke). (f) Mako shark Isurus oxyrinchus captured aboard a marine recreational fishing charter off Massachusetts, USA (Credit: Greg Skomal). 

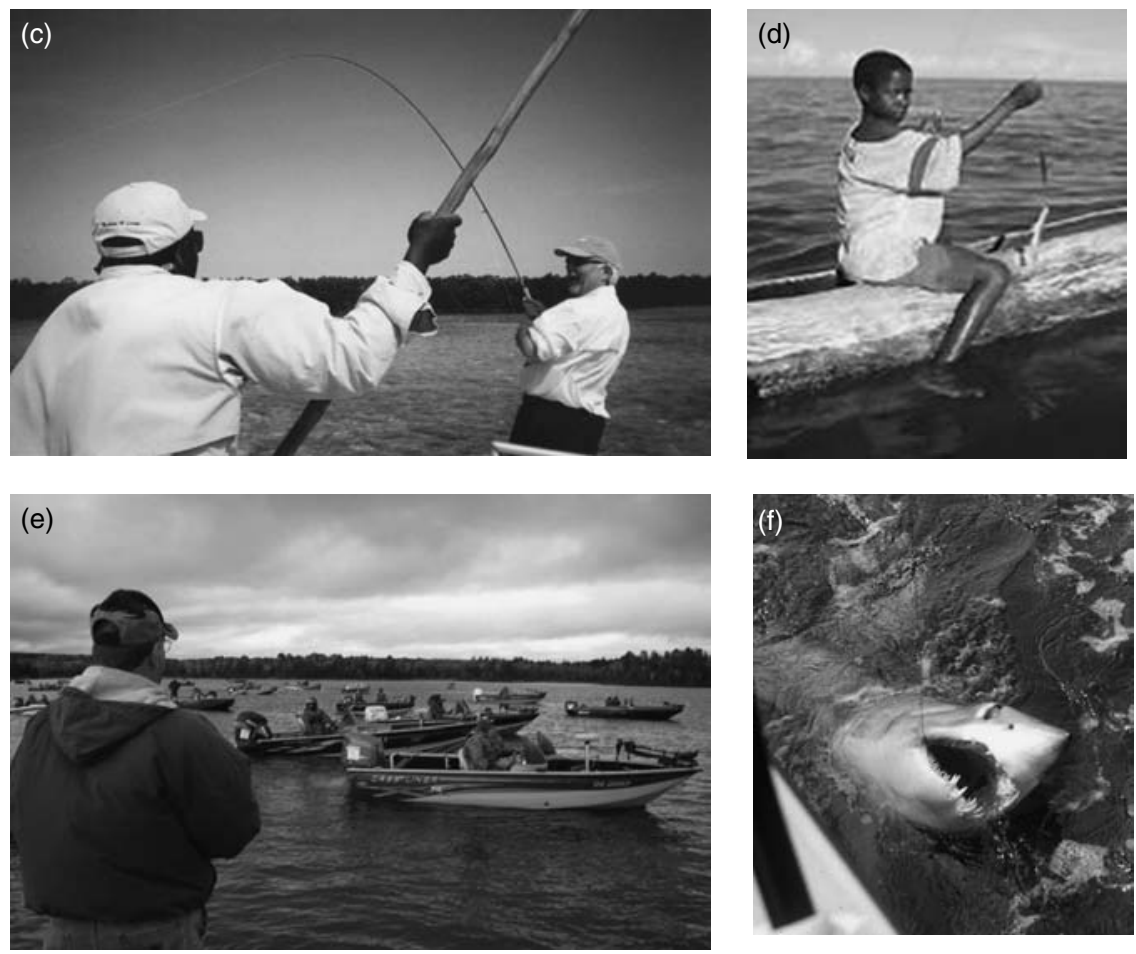

Figure 3.1 Continued.

\section{Participation and socioeconomic benefits}

Providing global estimates of participation in recreational fishing is difficult due to the lack of representative data from many regions of the world. Moreover, each of the available studies uses different sampling frames or defines recreational fishing differently. The best available data compiled here nevertheless suggest some remarkable trends in participation. For example, hotspots of recreational fishing participation are found in relatively sparsely populated but freshwater- or coastline-rich regions, such as the Scandinavian countries, Australia and North America (Figure 3.2). Recreational fishing participation in each of these 'participation hotspots' comprises more than 10 per cent of the adult population, with record values of close to 50 per cent recreational fishing participation found in the adult population of 
(44) Robert Arlinghaus and Steven J. Cooke

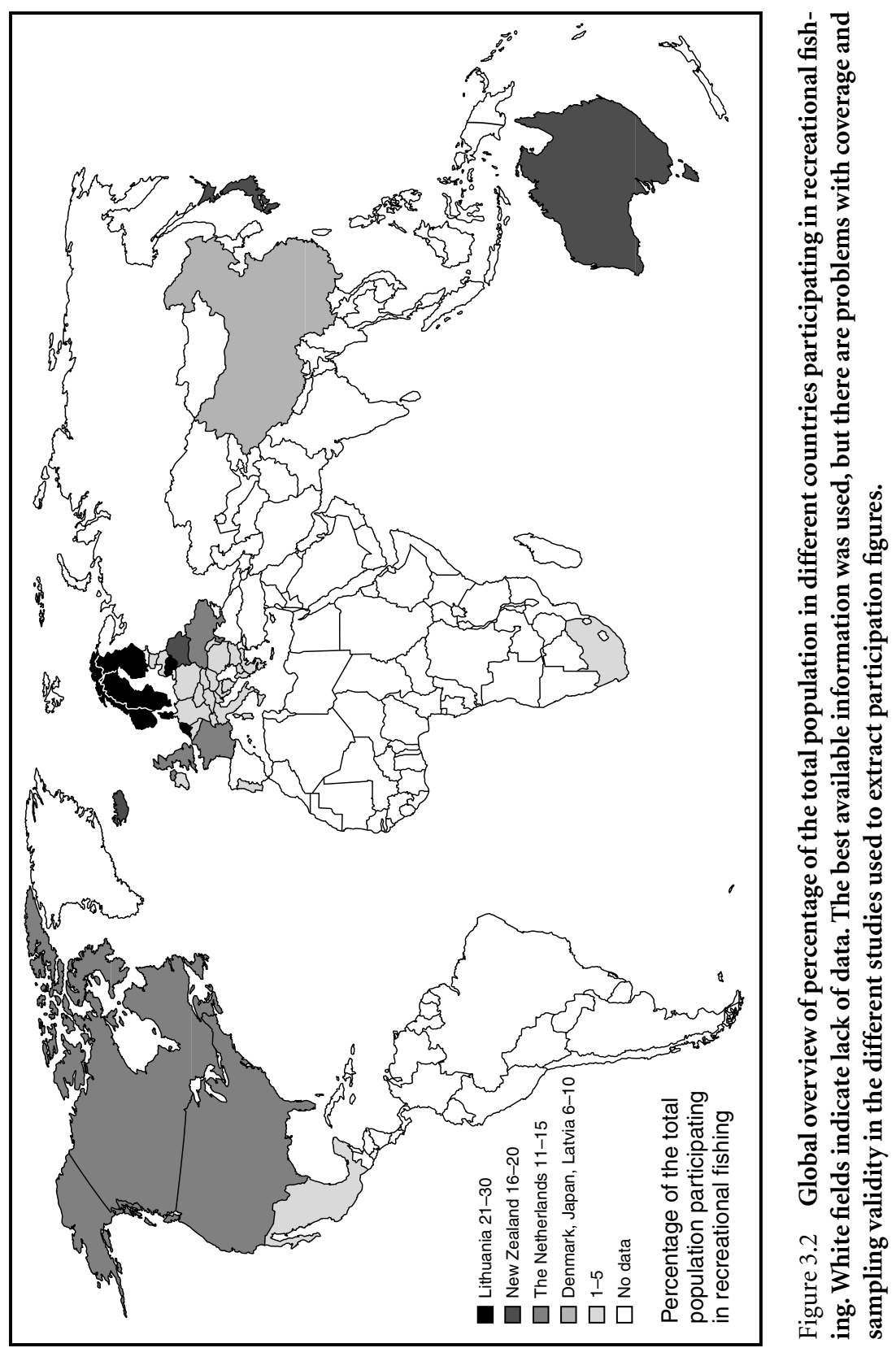


Norway. If available data are related to the total population, values of reported participation in recreational fishing range up to 32 per cent in Norway with a mean value of 10.6 per cent of the adult population. Cooke \& Cowx (2004) extrapolated from Canadian values that 0.73 billion people can be expected to fish recreationally worldwide (11.5 per cent of the global population). The low levels of participation in certain countries that are reported in the literature are likely to be the result of weak data rather than low participation overall. For example, recreational fishing participation is often reported to be low in southern Europe and many Eastern European countries, although it is well known that substantial number of people participate in this type of fishing, maybe more than in Central European countries.

The socioeconomic and ecological benefits generated by recreational fishing were comprehensively reviewed by Weithman (1999) and Arlinghaus et al. (2002), and are therefore only briefly mentioned here. These benefits include not only an increased quality of life for the recreational angler but also income accrued at local, regional and national levels in fishingexpenditure-dependent commercial activities (e.g. tackle shops). In North America, recreational anglers directly support fisheries management, conservation efforts and outdoor recreation opportunities through excise taxes and the purchase of licences, stamps, and equipment registration fees. Moreover, activity by recreational anglers can provide resources for the rural development of coastal areas of less developed nations. Kearney (1999) suggested that the conservation-conscious recreational fishing community represents one of the greatest potential forces for the conservation of aquatic biodiversity. Indeed, in some countries, fishery stakeholders such as angling associations have pushed governments to formulate environmental legislation and were the driving forces for several subsequent legal revisions (Kirchhofer, 2002). A Water Protection Act initiated by fishery associations in Switzerland in 1955 served as an important milestone in freshwater conservation. There are also examples of anglers' conservation associations (e.g. the Anglers' Conservation Association formed in 1948 in the UK) that have fought legal actions against environmental pollution (Bate, 2001). However, not all measures adopted by traditional recreational fisheries managers are beneficial to the conservation of fish populations, as will be shown below. Nevertheless, a relatively high proportion of society keeps in contact with nature through linkages with recreational fisheries and consequently tends to be more sensitive to environmental issues than the majority of an increasingly urban population. This awareness is central for an ecosystem approach to fisheries management and sustainability (Arlinghaus, 2006a). 


\section{Conservation issues}

Recreational fishing is facing a number of conservation issues, many of which were reviewed recently in Cooke \& Cowx (2006) and Lewin et al. (2006). A brief summary of these global syntheses follows.

\section{High exploitation}

Excessive exploitation of animal populations though elevated anthropogenic mortality represents one of the most prominent conservation issues shared by hunting and fishing (Mace \& Reynolds, 2001). Recreational fishing has only recently been recognised as a significant contributor to global fish declines, particularly on inland waters (Cooke \& Cowx, 2004, 2006), and some clear examples have now been presented (Post et al., 2002; Coleman et al., 2004). In recreational fishing, annual exploitation rates up to 80 per cent of the average standing stock have been reported, but there is huge variation from fishery to fishery, ranging from close to zero to very high values (Lewin et al., 2006). As long as the level of fishing is within the compensatory potential of the exploited species (for example, enhancement of growth and fecundity in response to human-induced population declines), extinction is very unlikely. There are no obvious examples where recreational fishing alone has led to the extinction of a species (Arlinghaus et al., 2002). However, this last statement does not preclude the potential for population declines or changes in structure of the exploited species (Lewin et al., 2006). The most important factors determining whether fishing causes a decline of fish populations are the life history of the species and the amount of angling effort. An impact is more likely if the exploited species has low fecundity and high age at maturation and is easily catchable due to the species' association with easily identifiable habitat structures (e.g. submerged macrophytes) (Post et al., 2002).

\section{Selective harvest and trophy issues}

Recreational fishing is usually selective with respect to species, size, ages, sex or behavioural and physiological traits (Lewin et al., 2006; Cooke et al., 2007). Selective exploitation results from factors such as the species preferences of anglers, fishing regulations that allow harvest of particular sizes or species, 
and the differential vulnerability of specific phenotypes (for example, faster growing fish, larger fish or bolder individuals) to the angling gear. Within some recreational fishing communities, there is also much emphasis placed on 'trophies', which are selectively targeted and may be removed from the system. Trophies are typically individuals that are exceptionally large, or have other phenotypic characteristics that make them attractive to the angler. Concern exists that harvest (or indirect mortality) of trophy, or more generally large, individuals (Birkeland \& Dayton, 2005) can have demographic or evolutionary effects on fish and wildlife populations (Jørgensen et al., 2007). In recreational fishing it is difficult to target a trophy, although there are many tourist operators that focus on providing anglers with the opportunity to fish for trophies. Populations may be managed to produce trophies or may do so intrinsically (for example, due to local climate and productivity). Unfortunately, many of the fish species that are currently rare and considered trophies also have life-history characteristics such as late age at maturity and low fecundity (Reynolds et al., 2001) that make them vulnerable to exploitation.

In addition to ecological changes such as truncation in age and size structure (Lewin et al., 2006), high and selective exploitation may result in evolutionary responses in the exploited population if some phenotypes experience higher mortality than others and thus are less able to reproduce (Jørgensen et al., 2007). Although noted for many years, the potential for fishing- or hunting-induced evolutionary changes has not been universally appreciated by fisheries and wildlife managers. This is in part due to the difficulty of providing conclusive evidence of this phenomenon in wild stocks because of phenotypic plasticity in life history or other adaptive traits and the associated difficulty in ascribing observed phenotypic changes to fishing-induced evolution. However, the prerequisites for evolutionary changes in fish populations in response to recreational fishing exist. These prerequisites include local adaptation, heritable population variation and a high and selective fishing mortality (Lewin et al., 2006), and the evidence that fishing might result in evolutionary changes is mounting (Jørgensen et al., 2007). Cooke et al. (2007) found that largemouth bass Micropterus salmoides differed in vulnerability to angling; individuals of high angling vulnerability differed from individuals with low vulnerability in a number of physiological and behavioural traits indicating the selective effect of angling on these traits. The notion that fishing can be selective should be more fully embraced by fish and wildlife managers in the future. 


\section{Harvest or disturbance during the reproductive period}

Many recreational fisheries intentionally or accidentally target fish during the reproductive period. This can have negative consequences on individual fitness, reproductive success and recruitment (Cooke et al., 2002). For example, Atlantic salmon Salmo salar are targeted during their upriver spawning migrations. Although many fish are released, warm water temperatures can lead to high levels of catch-and-release mortality (Wilkie et al., 1996). Smallmouth bass Micropterus dolomieu and largemouth bass provide sole paternal care during which time the parental male must fan the developing offspring in their nest and defend the offspring from potential brood predators. Removal of parental males leads to nest predation and increased rates of nest abandonment (Suski et al., 2003). Catching and releasing fish shortly before reproduction can also lead to reduced reproductive output and larval size-at-hatch (Ostrand et al., 2004), which is why many jurisdictions have implemented close seasons to protect fish during the reproductive period.

\section{Sub-lethal effects, wounding, and the one that 'got away'}

In recreational fishing, there are many fish that are landed and released with the assumption that they will survive. This regulatory or voluntary catchand-release can involve billions of fish world-wide (Cooke \& Cowx, 2004; Arlinghaus et al., 2007). However, given that post-release mortality rates range from about zero to near 90 per cent (Muoneke \& Childress, 1994; Bartholomew \& Bohnsack, 2005), the assumption that the released fish survive is not always valid. Nevertheless, anglers can make decisions on gear type (such as hook type, bait/lure or line strength, sometimes with direction in the form of regulation), which can influence the level of fishing-induced stress and injury. For example, organic or live baits tend to result in fish being hooked more deeply than artificial lures (Arlinghaus et al., 2008). In addition, the use of barbless hooks can reduce the time needed to remove the fish from the hook and thus reduce harmful air exposure, and the use of circle hooks can minimise deep hooking (Cooke \& Suski, 2005).

In fishing, there are always some fish that 'get away'. These are called dropoffs or break-offs. In drop-offs, the fish comes off the hook(s) prior to being landed. Break-off implies that the line was broken and that the hook(s) 
and bait or lure are left in the fish. It is sometimes assumed that breaking off will lead to reductions in growth (and potentially mortality) if foraging is retarded. However, there are also studies that showed that hooks can be evacuated if left inside the fish (Tsuboi et al., 2006). Overall, there is considerable evidence that mortality of caught-and-released fish and the associated sub-lethal impacts can be low or greatly reduced if the fish is appropriately handled and not released under unfavourable conditions (e.g., at very high water temperatures, or after being captured from deep water; Arlinghaus et al., 2007).

\section{Pollution and environmental disturbance}

Recent syntheses have revealed that recreational fishing can lead to environmental pollution and disturbance in a number of ways (Cooke \& Cowx, 2006; Lewin et al., 2006). For example, recreational anglers use boats to access inland and coastal habitats. Powerboats can cause the degradation of localised habitats, particularly in near-shore and inland environments, through wave-induced erosion of shorelines and increased suspension of sediment; they may also disturb both fish and wildlife (Wolter \& Arlinghaus, 2003). In addition, angling can disturb wildlife (especially birds) if access to waters or shoreline is uncontrolled (Cryer et al., 1987). Trampling of vegetation can cause alterations of habitat and negatively impact on invertebrates (Mueller et al., 2003).

Fishing activities generate litter, leading to localised habitat alteration. Litter such as fishing line and hooks can become entangled in various wildlife species, which can result in injury or mortality (e.g., Nemoz et al., 2004). However, the most contentious issue is the deposition of lead from fishing sinkers, which can create localised pollution and, if ingested (particularly by waterfowl), may result in lead poisoning and death (Scheuhammer et al., 2003).

In addition to inadvertent pollution, there is also 'intentional' pollution arising from using bait to attract animals. In fishing, ground-baiting (with cereals, maggots or other bait) or chumming, the process of distributing bait in water to attract fish, is common in both freshwater and marine environments. The excess nutrients from this activity (Arlinghaus \& Mehner, 2003; Niesar et al., 2004) can lead to a deterioration in water quality and a reduction in benthic fauna (Cryer \& Edwards, 1987). 


\section{Supplementation, stocking and introductions}

To support recreational fishing, many natural resource agencies supplement or stock endemic populations with additional animals that are either transferred from other locales or have been raised in captivity. Although an important management tool, stocking itself may cause conservation problems. For example, largemouth bass are widely stocked to enhance fishing opportunities in the United States. However, there is a growing body of evidence to suggest that fish stocking can cause problems for the recipient population (Molony et al., 2003) and the broader ecosystem (Holmlund \& Hammer, 2004), particularly if the stocked fish are not locally adapted to their new environment (Philipp et al., 2002). Outbreeding depression can arise in the recipient population leading to reduced growth rates, problems with immunocompetancy, and mortality (Philipp et al., 2002; Goldberg et al., 2005). In addition, captive-bred animals may be inferior to their wild conspecifics leading to changes in the recipient population (Molony et al., 2003).

Many species of fish have been introduced outside their endemic range in an effort to create new recreational angling opportunities. Rainbow trout Oncorhynchus mykiss, carp Cyprinus carpio and largemouth bass are three of the most widely introduced species. In some cases they have caused notable changes in community structure (reviewed in Cambray, 2003). Stocking and particularly introductions are among the most abused management tools in contemporary wildlife and fisheries management. Thorough risk analyses should be carried out before these practices are implemented (Arlinghaus et al., 2002).

\section{Management challenges}

The conservation issues identified above, coupled with the great popularity of recreational fishing, call for improved management to address the most contentious issues. Below, we present an abbreviated list of the most important management challenges faced by contemporary recreational fisheries stakeholders.

Declining participation: A common problem for recreational fishing in some countries is declining license sales (and presumably participation rate), particularly in North America (Fedler \& Ditton, 2001). These declines are the result 
of demographic change and an increasing urban population in which rural lifestyles and activities such as hunting and fishing are becoming less popular (Arlinghaus, 2006b). Considering that many of the proponents of angling and hunting are now from urban rather than rural environments (Franklin, 1998), there is interest in enhancing opportunities for urban fishing (Arlinghaus \& Mehner, 2004) in an attempt to reverse the decline.

Stakeholder conflicts: Fishing requires space and interacts with wild living organisms. At times, anglers and others engaged in recreation occupy the same space, generating conflict intrasectorally (Arlinghaus, 2005). However, one of the greatest sources of conflict in the future is likely to be fish welfare and the more fundamental and ideologically driven animal rights movement (Arlinghaus, 2005; Arlinghaus et al., 2007). For these stakeholders, hunting a wild animal for the sake of recreation is typically perceived as a cruel activity that should stop. This perspective conflicts with the value and belief system of many recreational anglers (Arlinghaus, 2005). There are jurisdictions such as Germany where the only accepted reason for fishing for recreation is the appropriation of food, and practices such as the use of live bait, competitive fishing or voluntary catch-and-release are not tolerated (Arlinghaus, 2007). Because of the similarities between hunting and fishing, we suggest that the way forward is to enhance the interaction between anglers, hunters and fish and wildlife managers in order to find ways to address animal welfare concerns in practice.

Controlling effort and harvest: In order to address the conservation issues identified in this paper, it is necessary to control or limit fish mortality. Although both fish and wildlife managers make extensive use of harvest regulations such as bag limits, the actual effect of these traditional harvest regulations is debatable (Radomski et al., 2001). Most regulations focus on controlling actual harvest or other sources of fish mortality through the use of size-based harvest limits and daily bag limits. This does not necessarily reduce total annual fish mortality as overall effort is not controlled. Nevertheless, there is some potential for self-regulation through dynamic fish-angler interactions. That is, some anglers will leave a fishery when fish abundance declines, and resume fishing if fish populations rebound. However, the potential for depensatory processes (i.e. a positive relation between the per capita population growth rate and population size at low population sizes rendering the population vulnerable to extinction) limits the self-regulatory capacity of some fish (and angler) populations (Post et al., 2002). There are instances where harvest 
controls alone have been ineffective in sustaining recreational fishing, resulting in calls to limit entry (and thus directly control effort) (Cox et al., 2002). To control angling effort and harvest recently the use of licence allocation lotteries and implementation of aquatic protected areas have been proposed. In the latter case, all fishing activities are typically prohibited, thus effectively reducing effort (and harvest) to zero. We predict a greater use of both harvest regulations and effort control means in the management of fish and wildlife and that a combination of these tactics will be locally effective depending on environmental conditions and the biology of the species targeted (Carpenter \& Brock, 2004).

Compliance: Fundamental to the function of management regulations for fish and wildlife is the need for high levels of compliance. Unfortunately, fishing suffers from less than perfect compliance (Muth \& Bowe, 1998; Sullivan, 2002), at times making management strategies falter or fail (Sullivan, 2002). Recent research efforts have focused on identifying a typology of the motivations for poaching which are common to both the hunting and angling sectors. Muth \& Bowe (1998) suggest that understanding the motivations behind noncompliance provides opportunities for developing strategies such as education to counter this activity.

\section{Outlook}

It is somewhat surprising that fish and wildlife populations continue to suffer overexploitation given that the fundamental principles underlying the regulation of exploitation have been known for many years (Sutherland, 2001). Although the principle of sustainability is entrenched in fishing philosophy (Arlinghaus et al., 2002), difficulties in developing scientifically sound and effective management strategies remain. One major constraint in recreational fishing is the diffuse nature of the activity, which makes it impossible to monitor the status of the exploited population accurately in space and time. However, for many years it was assumed that recreational fishing was a benign phenomenon. This assumption is beginning to be challenged with increasing research conducted on the topic.

Arlinghaus \& Cooke (2005) stressed that recreational fishing should be studied in the same way as commercial fishing. However, despite the many parallels that provide the grounds for unified efforts to conserve exploited wildlife (Cooke \& Cowx, 2006), it is also important to realise the differences between 
commercial fishing and recreational fishing and between recreational fishing and recreational hunting. For example, it is virtually impossible to develop monitoring systems for all recreational fisheries worldwide. This suggests the need for a 'rule of thumb' management approach that is framed in terms of active adaptive management and based on 'learning by doing' (Pereira \& Hansen, 2003; Arlinghaus, 2006a). However, it is also necessary to realise the social and economic benefits generated by both recreational fishing and hunting and the important capacity of these stakeholders to contribute resources and human capital to successful management and to fish and wildlife conservation. In many cases, recreational fishing can take place with minimal impact on the resources; however, a certain degree of biological impact needs to be accepted as long as this does not affect entire populations. However, this statement should not be misinterpreted to mean that laissez-faire management is the way of the future. In fact, some changes in approaches and management direction are sorely needed. For example, fisheries stakeholders might conclude that due to the largely irreversible alteration of habitat structure and function in most river fisheries in central Europe, enhancement of fish and wildlife populations through stocking, introductions, and translocations is the most appropriate strategy for increasing the sustainability of these activities. Unfortunately, this approach fails to recognise and address the causal agents that are preventing the development of sustainable recreational fish and wildlife populations, and only serves as a band-aid approach. There is growing interest in developing more integrative fish and wildlife management strategies that are adaptive to changing conditions in the long term (Arlinghaus, 2006a). To facilitate such approaches, there is an urgent need to integrate biological and social sciences with the aim of providing insights into the dynamics of the entire social-ecological system of recreational fisheries. A greater incorporation of lessons from social science is necessary in order to understand the human constraints on reconciling resource use and conservation (Arlinghaus, $2004,2005,2006 a)$. It remains to be seen whether increased funds and human capital are made available to pursue this route.

\section{Acknowledgements}

RA thanks Thomas Klefoth for help with Figure 3.2. SJC acknowledges the financial support of the Canadian Foundation for Innovation, the Ontario Research Foundation, and the Natural Sciences and Engineering Research 
Council of Canada. RA acknowledges support through the Adaptfish-project funded by the Leibniz-Community in Germany.

\section{References}

Aas, $\varnothing$. (2002) The next chapter: multicultural and cross-disciplinary progress in evaluating recreational fisheries. In Recreational Fisheries: Ecological, Economic and Social Evaluation, eds. T.J. Pitcher \& C.E. Hollingworth, pp. 252-263. Blackwell Science, Oxford.

Arlinghaus, R. (2004) A Human Dimensions Approach towards Sustainable Recreational Fisheries Management. Turnshare Ltd., London.

Arlinghaus, R. (2005) A conceptual framework to identify and understand conflicts in recreational fisheries systems, with implications for sustainable management. Aquatic Resources, Culture and Development, 1, 145-174.

Arlinghaus, R. (2006a) Overcoming human obstacles to conservation of recreational fishery resources, with emphasis on Europe. Environmental Conservation, 33, $46-59$.

Arlinghaus, R. (2006b) Understanding recreational angling participation in Germany: preparing for demographic change. Human Dimensions of Wildlife, 11, 229-240.

Arlinghaus, R. (2007) Voluntary catch-and-release can generate conflict within the recreational angling community: a qualitative case study of specialised carp, Cyprinus carpio, angling in Germany. Fisheries Management and Ecology, 14, 161-171.

Arlinghaus, R. \& Cooke, S.J. (2005) Global impact of recreational fisheries. Science, 307, 1561-1562.

Arlinghaus, R. \& Mehner, T. (2003) Socio-economic characterisation of specialised common carp (Cyprinus carpio L.) anglers in Germany, and implications for inland fisheries management and eutrophication control. Fisheries Research, 61, 19-33.

Arlinghaus, R. \& Mehner, T. (2004) A management-oriented comparative analysis of urban and rural anglers living in a metropolis (Berlin, Germany). Environmental Management, 33, 331-344.

Arlinghaus, R., Mehner, T. \& Cowx, I.G. (2002) Reconciling traditional inland fisheries management with sustainability in industrialized countries, with emphasis on Europe. Fish and Fisheries, 3, 261-316.

Arlinghaus, R., Cooke, S.J., Lyman, J. et al. (2007) Understanding the complexity of catch-and-release in recreational fishing: an integrative synthesis of global knowledge from historical, philosophical, social, and biological perspectives. Reviews in Fisheries Science, 15, 75-167.

Arlinghaus, R., Klefoth, T., Kobler, A. \& Cooke, S.J. (2008) Size-selectivity, capture efficiency, injury, handling time and determinants of initial hooking mortality of 
angled northern pike (Esox lucius L.): the influence of bait type and size. North American Journal of Fisheries Management, 28, 123-134.

Bartholomew, A. \& Bohnsack, J.A. (2005) A review of catch-and-release angling mortality with implications for no-take reserves. Reviews of Fish Biology and Fisheries, 15, 129-154.

Bate, R. (2001) Saving Our Streams: the Role of the Anglers' Conservation Association in Protecting English and Welsh Rivers. The Institute of Economic Affairs and Profile Books, London.

Birkeland, C. \& Dayton, P.K. (2005) The importance in fishery management of leaving the big ones. Trends in Ecology and Evolution, 20, 356-358.

Cambray, J.A. (2003) Impact on indigenous species biodiversity caused by the globalisation of alien recreational freshwater fisheries. Hydrobiologia, 500, 217-230.

Carpenter, S.R. \& Brock, W.A. (2004) Spatial complexity, resilience, and policy diversity: fishing on lake-rich landscapes. Ecology and Society, 9, 8. [online journal http://www.ecologyandsociety.org/vol9/iss1/art8]

Coleman, F.C., Figueira, W.F., Ueland, J.S. \& Crowder, L.B. (2004) The impact of United States recreational fisheries on marine fish populations. Science, 305, 1958-1960.

Cooke, S.J. \& Cowx, I.G. (2004) The role of recreational fishing in global fish crises. BioScience, 54, 857-859.

Cooke, S.J. \& Cowx, I.G. (2006) Contrasting recreational and commercial fishing: searching for common issues to promote unified conservation of fisheries resources and aquatic environments. Biological Conservation, 128, 93-108.

Cooke, S.J. \& Suski, C.D. (2005) Do we need species-specific guidelines for catch-andrelease recreational angling to conserve diverse fishery resources? Biodiversity and Conservation, 14, 1195-1209.

Cooke, S.J., Schreer, J.F., Dunmall, K.M. \& Philipp, D.P. (2002) Strategies for quantifying sublethal effects of marine catch-and-release angling - insights from novel freshwater applications. American Fisheries Society Symposium, 30, 121-134.

Cooke, S.J., Suski, C.D., Ostrand, K.G., Philipp, D.P. \& Wahl, D.H. (2007) Physiological and behavioral consequences of long-term artificial selection for vulnerability to recreational angling in a teleost fish. Physiological and Biochemical Zoology, 80, $480-490$.

Cowx, I.G. (2002) Recreational fishing. In Handbook of Fish Biology and Fisheries Vol. 2: Fisheries, eds. P.J.B. Hart \& J.D. Reynolds, pp. 367-390. Blackwell Science, Oxford.

Cox, S.P., Beard, T.D. \& Walters, C. (2002) Harvest control in open-access sport fisheries: Hot rod or asleep at the reel? Bulletin of Marine Science, 70, 749-761.

Cryer, M. \& Edwards, R.W. (1987) The impact of angler groundbait on benthic invertebrates and sediment respiration in a shallow eutrophic reservoir. Environmental Pollution, 46, 137-150. 
Cryer, M., Whittle, G.N. \& Williams, R. (1987) The impact of bait collection by anglers on marine intertidal invertebrates. Biological Conservation, 42, 83-93.

Food and Agricultural Organization of the United Nations (FAO) (1997) Inland fisheries. FAO Technical Guidelines for Responsible Fisheries, 6, 1-38.

Fedler, A.J. \& Ditton, R.B. (1994) Understanding angler motivations in fisheries management. Fisheries, 19(4), 6-13.

Fedler, A.J. \& Ditton, R.B. (2001) Dropping out and dropping in: a study of factors for changing recreational fishing participation. North American Journal of Fisheries Management, 21, 283-292.

Franklin, A. (1998) Naturalizing sports: hunting and angling in modern environments. International Review for the Sociology of Sport, 33, 355-366.

Goldberg, T.L., Grant, E.C., Inendino, K.R., Kassler, T.W., Claussen, J.E. \& Philipp, D.P. (2005) Increased infectious diseases susceptibility resulting from outbreeding depression. Conservation Biology, 19, 455-462.

Holmlund, C.M. \& Hammer, M. (2004) Effects of fish stocking on ecosystem services: an overview and case study using the Stockholm archipelago. Environmental Management, 33, 799-820.

Jørgensen, C., Enberg, K., Dunlop, E.S. et al. (2007) Managing evolving fish stocks. Science, 318, 1247-1248.

Kearney, B. (1999) Evaluating recreational fishing: managing perceptions and/or reality. In Evaluating the Benefits of Recreational Fisheries, ed. T.J. Pitcher, pp. 9-14. The Fisheries Centre, Vancouver.

Kirchhofer, A. (2002) The role of legislation, institutions and policy making in fish conservation in Switzerland: past, present and future challenges. In Conservation of Freshwater Fish: Options for the Future, eds. M.J. Collares-Pereira, I.G. Cowx \& M.M. Coelho, pp. 389-401. Blackwell Science, Oxford.

Lewin, W.C., Arlinghaus, R. \& Mehner, T. (2006) Documented and potential biological impacts of recreational angling: insights for conservation and management. Reviews in Fisheries Science, 14, 305-367.

Mace, G.M. \& Reynolds, J.D. (2001) Exploitation as a conservation issue. In Conservation of Exploited Species, eds. J.D. Reynolds, G.M. Mace, K.H. Redford \& J.G. Robinson, pp. 4-15. Cambridge University Press, Cambridge.

Molony, B.W., Lenanton, R., Jackson, G. \& Norriss, J. (2003) Stock enhancement as a fisheries management tool. Reviews in Fish Biology and Fisheries, 13, 409-432.

Mueller, Z., Jakab, T., Toth, A. et al. (2003) Effects of sports fisherman activities on dragonfly assemblages on a Hungarian river floodplain. Biodiversity and Conservation, $12,167-179$.

Muoneke, M.I. \& Childress, W.M. (1994) Hooking mortality: a review for recreational fisheries. Reviews in Fisheries Science, 2, 123-156. 
Muth, R.M. \& Bowe, J.F. (1998) Illegal harvest of renewable natural resources in North America: toward a typology of the motivations for poaching. Society and Natural Resources, 11, 9-24.

Nemoz, M., Cadi, A. \& Thienpont, S. (2004) Effects of recreational fishing on survival in an Emys orbicularis population. Biologia, 59, 185-189.

Niesar, M., Arlinghaus, R., Rennert, B. \& Mehner, T. (2004) Coupling insights from a carp (Cyprinus carpio L.) angler survey with feeding experiments to evaluate composition, quality, and phosphorus input of groundbait in coarse fishing. Fisheries Management and Ecology, 11, 225-235.

Ostrand, K.G., Cooke, S.J. \& Wahl, D.H. (2004) Effects of stress on largemouth bass reproduction. North American Journal of Fisheries Management, 24, 1038-1045.

Pereira, D.L. \& Hansen, M.J. (2003) A perspective on challenges to recreational fisheries management: summary of the symposium on active management of recreational fisheries. North American Journal of Fisheries Management, 23, 1276-1282.

Philipp, D.P., Claussen, J.E., Kassler, T.W. \& Epifanio, J.M. (2002) Mixing stocks of largemouth bass reduces fitness through outbreeding depression. American Fisheries Society Symposium, 31, 349-363.

Pitcher, T.J. \& Hollingworth, C.E. (eds.) (2002) Recreational Fisheries: Ecological, Economic and Social Evaluation. Blackwell Science, Oxford, pp. 1-16.

Policansky, D. (2002) Catch-and-release recreational fishing: a historical perspective. In Recreational Fisheries: Ecological, Economic and Social Evaluation, eds. T.J. Pitcher \& C.E. Hollingworth, pp. 74-94. Blackwell Science, Oxford.

Post, J.R., Sullivan, M., Cox, S. et al. (2002) Canada's recreational fisheries: the invisible collapse? Fisheries, 27(1), 6-15.

Radomski, P.J., Grant, G.C., Jacobson, P.C. \& Cook, M.F. (2001) Visions for recreational fishing regulations. Fisheries, 26(5), 7-18.

Reynolds, J.D., Jennings, S. \& Dulvy, N.K. (2001) Life histories of fishes and population responses to exploitation. In Conservation of Exploited Species, eds. J.D. Reynolds, G.M. Mace, K.H. Redford, \& J.G. Robinson, pp. 148-168. Cambridge University Press, Cambridge.

Scheuhammer, A.M., Money, S.L., Kirk, D.A. \& Donaldson, G. (2003) Lead fishing sinkers and jigs in Canada: review of their use patterns and toxic impacts on wildlife. Technical Report No.: CW69-1/108E. Canadian Wildlife Service, Ottawa.

Sullivan, M.G. (2002) Illegal angling harvest of walleyes protected by length limits in Alberta. North American Journal of Fisheries Management, 22, 1053-1063.

Suski, C.D., Svec, J.H., Ludden, J.B., Phelan, F.J.S. \& Philipp, D.P. (2003) The effect of catch-and-release angling on the parental care behaviour of male smallmouth bass. Transactions of the American Fisheries Society, 132, 210-218.

Sutherland, W.J. (2001) Sustainable exploitation: a review of principles and methods. Wildlife Biology, 7, 131-140. 


\section{8}

Tsuboi, J., Morita, K. \& Ikeda, H. (2006) Fate of deep-hooked white spotted charr after cutting the line in a catch-and-release fishery. Fisheries Research, 79, 226-230.

Weithman, A.S. (1999) Socioeconomic benefits of fisheries. In Inland Fisheries Management in North America, 2nd edn., eds. C.C. Kohler \& W.A. Hubert, pp. 193-213. American Fisheries Society, Bethesda, Maryland.

Wilkie, M.P., Davidson, K., Brobbel, M.A. et al. (1996) Physiology and survival of wild Atlantic salmon following angling in warm summer waters. Transactions of the American Fisheries Society, 125, 572-580.

Wolter, C. \& Arlinghaus, R. (2003) Navigation impacts on freshwater fish assemblages: the ecological relevance of swimming performance. Reviews in Fish Biology and Fisheries, 13, 63-89. 